\title{
Mixed states vs. pure mania in the french sample of the EMBLEM study: results at baseline and 24 months - European mania in bipolar longitudinal evaluation of medication
}

\author{
Jean-Michel Azorin ${ }^{1}$, Elodie Aubrun², Jordan Bertsch ${ }^{3}$, Catherine Reed ${ }^{4}$, \\ Stephanie Gerard ${ }^{2}$ and Michael Lukasiewicz*2
}

Address: ${ }^{1}$ SHU psychiatrie adulte, CHU Ste Margueritte, Marseille, France, ${ }^{2}$ Neurosciences Medical department, Eli Lilly and company, Suresnes, France, ${ }^{3}$ Fundacio Sant Joan de Déu, Serveis de Salut Mental, Hospital Sant Joan de Déu, Barcelona, Spain and ${ }^{4}$ European Health Outcomes, Eli Lilly and company, Windlesham, UK

Email: Jean-Michel Azorin - ajazorin@ap-hm.fr; Elodie Aubrun - aubrunelodie@yahoo.fr; Jordan Bertsch - jbertsch@sjd-ssm.com; Catherine Reed - reed_catherine@lilly.com; Stephanie Gerard - gerardst@lilly.com; Michael Lukasiewicz* - lukasiewicz_michael@lilly.com

* Corresponding author

Published: 7 June 2009

BMC Psychiatry 2009, 9:33 doi:10.1186/147|-244X-9-33
Received: 29 October 2008

Accepted: 7 June 2009

This article is available from: http://www.biomedcentral.com/I47I-244X/9/33

(C) 2009 Azorin et al; licensee BioMed Central Ltd.

This is an Open Access article distributed under the terms of the Creative Commons Attribution License (http://creativecommons.org/licenses/by/2.0), which permits unrestricted use, distribution, and reproduction in any medium, provided the original work is properly cited.

\begin{abstract}
Background: To describe the clinical course and treatment patterns over 24 months of patients experiencing an acute manic/mixed episode within the standard course of care.

Methods: EMBLEM was a 2-year European prospective, observational study on outcomes of patients experiencing a manic/mixed episode. Adults with bipolar disorder were enrolled within the standard course of care as in/outpatients if they initiated or changed oral medication for treatment of acute mania. After completing 12 weeks of acute phase, patients were assessed every 3-6 months during the maintenance phase. We present the 24 month results, with subgroup analysis for mixed states (MS) and pure mania (PM). These subgroup analyses are driven by the high proportion of antidepressants prescribed in this cohort.

Results: In France, 77 I patients were eligible for the maintenance phase. $69 \%$ of patients completed the follow up over 24 months. The mean age was 45.5 years (sd $=13.6)$ with $57 \%$ of women. $504(66 \%)$ patients were experiencing a PM and $262(34 \%)$ a MS at baseline. The main significant differences in MS vs. PM at baseline were: a higher rate of women, and in the previous 12 months, a higher frequency of episodes (manic/mixed and depressive), more suicide attempts, more rapid cycling, fewer social activities and more work impairment. Over the 24 months of follow-up the MS group had a significantly lower recovery than PM ( $36 \%$ vs. $46 \%, p=0.006)$. Overall, $42 \%$ of all patients were started on monotherapy and $58 \%$ on combination therapy; of those $35 \%$ and $30 \%$ respectively remained on their initial medication throughout the 24 months. At baseline, $36 \%$ were treated with an antidepressant, this proportion remains high throughout the follow-up period, with a significantly higher rate for MS vs. PM at 24 months ( $55 \%$ vs. $27 \%, \mathrm{p}<0.001$ ).

Conclusion: In this large sample, MS occur frequently (34\%), they are more severe at baseline and have a worse functional prognosis than PM. Although antidepressants are not recommended in MS and PM, they were frequently prescribed at baseline and are maintained during the 24 months of follow-up.
\end{abstract}




\section{Background}

Bipolar disorder is a chronic pathology, the course of which is marked by relapses and remissions. Long-term treatment in this pathology is necessary in order to minimize the risks of relapse and recurrence and also to allow optimal quality of life as well as social and personal functioning [1,2]. Therapeutic options for the treatment of acute manic episodes have widened with the availability of atypical antipsychotics. Some international guidelines $[1,2]$ have been updated with regard to the drug treatment of patients experiencing mania, but there has been no assessment as yet of their application in medical practice.

Mania comes in different forms (pure mania, mixed episode, psychosis and/or hallucination) and follows different patterns of progression (first episode, recurrence, rapid cycling, substance abuse). With such a wide variety of presentations, diagnosis of mixed states (MS) is particularly difficult $[3,4]$. MS are thought to be under-diagnosed and their prevalence not known to any degree of precision (between $6.7 \%$ and $37 \%$ depending on the sources) $[4,5]$, due mainly to a lack of a consensual definition [6] and also to misleading symptomatology. The depressed state the patients may present with could be the reason for prescribing anti-depressants, although these are not indicated. The course of MS could consequently deteriorate, including a heightened risk of suicide and substance abuse [7].

A previous analysis of the EMBLEM study highlighted the high proportion of antidepressants initially prescribed, suggesting that an associated depressive symptomatology is frequent. These observations support the case for a separate analysis of mixed states (MS) and pure mania (PM).

The European Mania in Bipolar Longitudinal Evaluation of Medication (EMBLEM) study was a prospective, observational study aimed at evaluating long and short term outcomes of patients presenting a manic or a mixed episode and at assessing the clinical and functional outcomes [812 ]. The results presented in this article come from the French cohort over a 24-month follow-up period.

\section{Methods \\ Study design}

The European Mania in Bipolar Longitudinal Evaluation of Medication (EMBLEM) study is a prospective, observational study conducted since 2002 in 14 European countries (Belgium, Denmark, Finland, France, Germany, Greece, Ireland, Italy, the Netherlands, Norway, Portugal, Spain, Switzerland and the UK), 4 of which (Denmark, Germany, Spain and Switzerland) did not take part in the maintenance phase. This study was approved by regulatory authorities and Ethics Committees in each participating country where required. In France, this study was approved by national medicinal council, CCTIRS (predata privacy committee) and CNIL (data privacy committee).

The acute phase of the study lasted for 12 weeks and included 5 post-baseline follow-up visits at 1, 2, 3, 6 and 12 weeks following the onset of antimanic treatment. During the maintenance phase, the patients were assessed at 6, 12, 18 and 24 months. Patients gave their informed consent for taking part in the study and confidentiality was kept in compliance with the law on information and liberty.

\section{Population}

To be included, patients had to be aged 18 years or over, presenting as in- or out-patients for the treatment of acute or mixed mania, and initiating or changing oral medication for mania (except for a change of dosage). Investigators were asked, but not obliged, to include in the study an equal number of patients initiated respectively under olanzapine and any other antimanic treatments (neuroleptics, antiepileptics and/or lithium). Treatment decisions were made prior to the decision to participate in the study and all treatment decisions were left at the discretion of the treating psychiatrist. To be eligible for analysis patients needed to have completed the acute phase of the study and be able to participate in the maintenance phase and to have no missing CGI-BP mania or depression ratings at baseline.

\section{Measurements and Variables}

Baseline data included patient socio-demographic characteristics, psychiatric history, treatments prescribed (previously prescribed, prescribed for the episode, concomitant medications). The mania/mixed and depressive symptomology and severity were assessed by various scales at baseline and during the subsequent visits: the Young Mania Rating Scale YMRS [13], the Hamilton Depression Rating Scale (modified version of 5 items, tailored to the depressive symptoms of the manic episode) [14] and the Clinical Global Impression - Bipolar Disorder (CGI-BP) scales - sub-scores of overall bipolar symptoms, manic symptoms, depressive symptoms and CGI-BP for hallucinations and delusions [15]. Diagnosis of mixed state was not reported systematically and a dimensional definition was subsequently used. Patients with a score of over 3 on the CGI-BP-mania and CGI-BP-depression scales at baseline were defined as mixed.

"Simple" remissionwas defined for patients with a CGI-BP overall under 3 for 2 consecutive visits with no relapse between the visits. Recovery was defined for patient experiencing a remission and not dissatisfied with life and social functioning is adequate (i.e. no work impairment, independent accommodation and at least 4 social activi- 
ties in the previous 4 weeks or with a partner (live-in or not live-in).

Relapse was defined for patients not achieving simple remission and patients meeting one of the 3 following relapse criteria: increase in CGI-BP overall since the last visit, with a score of 4 or more, admission to hospital for an acute episode of bipolar disorder and psychiatrist's opinion. Recurrence was defined for patients in simple remission and who met one of the three previous relapse criteria.

\section{Statistical methods}

Most of the results are given in the form of descriptive statistics. Continuous variables are expressed through means and the standard deviation and a Student test was used for comparison. Categorical variables are expressed as percentages and a $\chi^{2}$ test was used for comparison. Survival probabilities were estimated using the Kaplan Meier method and the log rank test was used for comparison. All the tests were carried out in a bilateral situation and the critical value of alpha was set for $\mathrm{p}=0.05$. Given that this was an exploratory study we did not correct for multiple comparisons.

\section{Results \\ Population -Socio-demographic data}

Of the 795 French patients recruited during the acute phase (equivalent to a third of the European cohort $\mathrm{n}=$ 2357), between December 1, 2002 and June 30, 2004, 771 patients were eligible for the maintenance phase. The total population was finally 766 patients (because of 5 missing data concerning the diagnosis) (57\% female). At baseline, 504 (66\%) PM and 262 (34\%) MS were reported. $69 \%(n=528)$ of the patients completed the 24 months of the follow-up period. The proportion of patients who withdrew from the trial was significantly higher among those presenting a mixed episode at baseline $(37 \%$ vs. $28 \%, \mathrm{p}=0.006)$.

The mean age of the population was 45.5 years. Half the patients $(\mathrm{n}=380)$ had received high-school or university education, two thirds (64\%) had a partner and a majority $(77 \%)$ had an independent residence. The only significant difference between MS and PM at baseline was the higher proportion of females in the MS group (69\% vs. $51 \%$, p < 0.001) (Table 1).

\section{Psychiatric history}

The mean age of onset of symptoms of a bipolar disorder was 30.2 years, and onset was earlier in the MS group compared to the PM (28.9 years vs. 30.9 years, $\mathrm{p}=0.004$ ).

In the 12 months prior to baseline, $37 \%$ of all patients had at least one manic/mixed episode. The prevalence and frequency of previous depressive and manic/mixed episodes was higher in the MS population (Table 1). 81 (11\%) of the patients had attempted suicide. The MS population showed a higher incidence of suicide attempts $(19 \%$ vs. $6 \%, \mathrm{p}<0.001)$ and rapid cycling $(26 \%$ vs. $11 \%$, $\mathrm{p}<0.001)$ in the past 12 months.

\section{Current episode}

At baseline, the mean overall score on the YMRS was 26.7, (27.4 for the PM and 25.3 for the MS, $\mathrm{p}=0.001$ ) (Table 2). The mean score was $4.7( \pm 0.9)$ for the CGI-BP-mania and $2.6( \pm 1.7)$ for the CGI hallucinations and delusions.

One patient out of four (25\%) took no part in social activities over the four weeks before baseline $(29 \%$ of the MS and $22 \%$ of the PM, $\mathrm{p}=0.009$ ). $83 \%$ of patients reported work impairment, which was higher for the MS ( $89 \%$ vs. $81 \%, \mathrm{p}=0.003) .63 \%$ of the MS vs. $40 \%$ of the PM expressed dissatisfaction with life $(\mathrm{p}<0.001)$.

\section{Assessment at 24 months (Tables 2 \&3)}

The mean scores on all the clinical impression scales decreased during the 24-month follow-up period, indicating improving symptoms. Patient outcome over the 24 months was estimated by analyzing survival distributions (Kaplan-Meier estimations). 57\% of MS patients experienced a relapse over the 24 months and $53 \%$ of the PM (p $=0.328, \mathrm{NS}) .19 \%$ of the MS experienced a recurrence at 24 months (vs. $12 \%$, NS p $=0.267$ ).

The "simple" remission rate was comparable between the MS patients (62\%) and the PM (61\%). The recovery rate, however, differed significantly between the PM and MS patients over the 24 months ( $46 \%$ for the PM vs. $36 \%$ for the MS, $\mathrm{p}=0.006$ ).

Most of the patients ( $88 \%$ ) had at least one social activity during the four weeks prior to the last follow-up visit, against $75 \%$ at baseline. The proportion of patients reporting impairment in their work activities reduced to $52 \%(46 \%$ in the PM and $65 \%$ in the MS p < 0.001$)$. After 24 months, over two thirds (70\%) of the patients considered they were satisfied with life (76\% of the PM and 59\% of the MS, p < 0.001) and only $9 \%$ of the patients were still dissatisfied $(5 \%$ of the PM and $18 \%$ of the MS patients), against $48 \%$ at baseline.

\section{Medication}

Previous medication

At baseline, before the onset of the new treatment, 283 patients $(37 \%)$ were not receiving any antimanic treatment (Table 4), 290 (38\%) were on monotherapy and 193 (25\%) on antimanic combinations. Of the antimanic agents, the most commonly prescribed (31\%) were anticonvulsants, then typical antipsychotics (29\%), atypical 
Table I: Baseline socio-demographic and clinical data of the French cohort $(n=766)$

\begin{tabular}{|c|c|c|c|}
\hline & Pure Mania & Mixed episode & $\mathrm{p}$-value ** \\
\hline & $\mathrm{n}=504$ & $n=262$ & \\
\hline \multicolumn{4}{|l|}{ Socio-demographic data: } \\
\hline Age (Mean $\pm S D)$ & $45.7 \pm 13.9$ & $45.1 \pm 13.1$ & N.S. \\
\hline \multicolumn{4}{|l|}{ Gender: } \\
\hline Male (n,\%) & $231(46 \%)$ & $73(28 \%)$ & $<0.001$ \\
\hline Female $(n, \%)$ & $257(51 \%)$ & $182(69 \%)$ & \\
\hline \multicolumn{4}{|l|}{ Educational level $(n, \%)$ : } \\
\hline None & $8(2 \%)$ & $4(2 \%)$ & N.S. \\
\hline Primary & $85(17 \%)$ & $37(14 \%)$ & \\
\hline Junior high school/apprenticeship & $156(31 \%)$ & $88(34 \%)$ & \\
\hline Secondary & $130(26 \%)$ & $69(26 \%)$ & \\
\hline University & $123(24 \%)$ & $58(22 \%)$ & \\
\hline \multicolumn{4}{|l|}{ Marital status(n,\%): } \\
\hline No partner & 175 (35\%) & $96(37 \%)$ & N.S. \\
\hline Living with partner & $229(45 \%)$ & $121(46 \%)$ & \\
\hline Not living with partner & 99 (20\%) & $43(16 \%)$ & \\
\hline \multicolumn{4}{|l|}{ Type of residence(n,\%): } \\
\hline Dependent & $|2|(24 \%)$ & $56(21 \%)$ & N.S. \\
\hline Independent & $383(76 \%)$ & 206 (79\%) & \\
\hline
\end{tabular}

\section{History:}

Age at onset of symptom(s):

$($ Mean \pm SD)

Age at first admission to hospital (Mean \pm SD)

No. of manic episodes in the past 12 months

(including current episode):

$\begin{array}{rllc}\text { Bipolar } & 30.9 \pm 11.1 & 28.9 \pm 11.3 & 0.036 \\ \text { Manic } & 32.5 \pm 11.8 & 30.9 \pm 12.8 & \text { N.S. } \\ \text { Depressive } & 32.3 \pm 11.0 & 29.4 \pm 11.3 & 0.004 \\ & 32.0 \pm 11.7 & 31.6 \pm 12.3 & \text { N.S }\end{array}$

No. of depressive episodes in the past 12 months:

$\begin{array}{rccc}\text { I } & 305(61 \%) & 130(50 \%) & 0.009 \\ >1 & 173(34 \%) & 108(41 \%) & \\ \text { Unknown } & 24(5 \%) & 22(8 \%) & \\ & & & <0.00 \text { I } \\ \text { None } & 246(49 \%) & 62(24 \%) & \\ \leq 2 & 214(42 \%) & 148(56 \%) & \\ >2 & 14(3 \%) & 30(11 \%) & <0.00 \text { I }\end{array}$

Past suicide attempts $(\mathrm{n}, \%)$

$32(6 \%)$

$<0.001$

\section{Current episode: \\ Rapid cycle * $(\mathrm{n}, \%)$

\footnotetext{
* Rapid cycle: at least 4 depressive or manic episodes in the past 12 months

** $\mathrm{p}$-value with significant threshold of a type I error $\alpha=0.05$

N.S. = not significant
}

$55(11 \%)$

$68(26 \%)$

$<0.00$ I

antipsychotics (AAP) (14\%) and lithium (13\%). Compliance was low, with $16 \%$ of the patients reporting they were compliant half the time and $6 \%$ of patients noncompliant. Concomitant treatments were frequent (antidepressants (36\%), benzodiazepines (58\%), hypnotics (32\%)). The only differences reported between MS and PM were antidepressant prescriptions (53\% for the MS vs. $28 \%, \mathrm{p}<0.001)$ and benzodiazepines (68\% for the MS vs. $53 \%, \mathrm{p}<0.001)$.
Treatment of the manic/mixed episode

The initiated or changed oral treatment was mostly (58\%) a combination of antimanic drugs, especially in the PM patients $(63 \%$ vs. $50 \%, \mathrm{p}<0.001)$. The most commonly prescribed drugs for the episode were AAP (63\%), typical antipsychotics (30\%) and lithium (14\%). Two thirds of the AAP $(n=311)$ were prescribed in combination, the majority with an anticonvulsant (53\%). The AAP + lithium combination was common in the MS (16\% vs. $11 \%$ for the PM). 
Table 2: Severity of the illness at baseline and at 24 months.

\begin{tabular}{|c|c|c|c|c|}
\hline & \multicolumn{2}{|c|}{ Pure Mania } & \multicolumn{2}{|c|}{ Mixed episode } \\
\hline & $\begin{array}{l}\text { Baseline } \\
n=504\end{array}$ & $\begin{array}{c}24 \text { months } \\
n=364(72 \%)\end{array}$ & $\begin{array}{l}\text { Baseline } \\
n=262\end{array}$ & $\begin{array}{c}24 \text { months } \\
n=164(63 \%)\end{array}$ \\
\hline \multicolumn{5}{|l|}{ Consultation (n,\%): } \\
\hline Out-patient & 352 (70\%) & $354(97 \%)$ & $169(65 \%)$ & 156 (95\%) \\
\hline In-patient & $152(30 \%)$ & $9(2 \%)$ & $92(35 \%)$ & $7(4 \%)$ \\
\hline \multicolumn{5}{|l|}{ Suicide attempt: } \\
\hline the & $46 \mid$ (9l\%)* & $317(87 \%)^{*}$ & $207(79 \%)^{*}$ & $|2|(74 \%)^{*}$ \\
\hline I & $22(4 \%)^{*}$ & $32(9 \%)^{*}$ & $26(10 \%)^{*}$ & 29 (I8\%)* $^{*}$ \\
\hline$>1$ & $10(2 \%)^{*}$ & $15(4 \%)^{*}$ & $23(9 \%)^{*}$ & $14(9 \%)^{*}$ \\
\hline \multicolumn{5}{|l|}{ Substance abuse and dependence $(n, \%)$ : } \\
\hline Alcohol & $128(25 \%)$ & $9(2 \%)$ & $70(27 \%)$ & 7 (4\%) \\
\hline Cannabis & $72(14 \%)$ & $8(2 \%)$ & $28(11 \%)$ & $3(2 \%)$ \\
\hline Other substances & $29(6 \%)$ & $2(<1 \%)$ & $25(10 \%)$ & $0(0 \%)$ \\
\hline \multicolumn{5}{|l|}{ Assessment scales: } \\
\hline YMRS (mean score \pm SD) & $27.4 \pm 8.8^{*}$ & (a) & $25.3 \pm 9.0^{*}$ & (a) \\
\hline \multicolumn{5}{|l|}{ CGI (mean score \pm SD): } \\
\hline CGI-BP Overall & $4.5 \pm 1.2$ & $2.4 \pm 1.6$ & $4.7 \pm 0.8$ & $2.5 \pm 1.4$ \\
\hline CGI-BP Mania & $4.8 \pm 0.9 *$ & $1.9 \pm 1.5$ & $4.6 \pm 0.8^{*}$ & $2.0 \pm 1.3$ \\
\hline CGI-BP Depression & $1.4 \pm 0.5^{*}$ & $1.5 \pm 0.9 *$ & $3.9 \pm 0.9 *$ & $2.1 \pm 1.2^{*}$ \\
\hline CGI-BP Hallucinations & $2.7 \pm 1.7$ & $1.4 \pm 0.9 *$ & $2.5 \pm 1.6$ & $1.6 \pm 1.1^{*}$ \\
\hline \multicolumn{5}{|l|}{ Frequency of social activities (n,\%): } \\
\hline Never & $112(22 \%)^{*}$ & $44(12 \%)$ & $77(29 \%)^{*}$ & $19(12 \%)$ \\
\hline I -4 times & $219(43 \%) *$ & $150(41 \%)$ & $116(44 \%)^{*}$ & 91 (55\%) \\
\hline$\geq 5$ times & $171(34 \%)^{*}$ & $169(46 \%)$ & $69(26 \%)^{*}$ & $53(32 \%)$ \\
\hline \multicolumn{5}{|l|}{ Impairment of work activities $(n, \%)$ : } \\
\hline None & $70(14 \%)^{*}$ & $175(48 \%)^{*}$ & $18(7 \%)^{*}$ & $5 \mathrm{I}(3 \mid \%)^{*}$ \\
\hline Some impairment & 406 (81\%)* & $166(46 \%)^{*}$ & $233(89 \%)^{*}$ & $106(65 \%)^{*}$ \\
\hline \multicolumn{5}{|l|}{ Satisfaction with life $(n, \%)$ : } \\
\hline Satisfied & 160 (32\%)* & $276(76 \%)^{*}$ & $47(18 \%)^{*}$ & $96(59 \%)^{*}$ \\
\hline Neither satisfied nor dissatisfied & $138(27 \%)^{*}$ & $68(19 \%)^{*}$ & $47(18 \%)^{*}$ & $37(23 \%) *$ \\
\hline Dissatisfied & $204(40 \%) *$ & $20(5 \%)^{*}$ & $166(63 \%)^{*}$ & $30(18 \%)^{*}$ \\
\hline
\end{tabular}

(a)The YMRS scale was not assessed at the TIO visit, at 24 months.

$*=$ There is a significant difference between the Pure Mania and Mixed Episode patient groups, threshold $\alpha=0.05$.

Prescriptions of antidepressants and benzodiazepines were common, with $27 \%$ of patients taking antidepressants $(15 \%$ of the PM and $49 \%$ of the MS, p < 0.001$)$ and $62 \%$ taking benzodiazepines ( $58 \%$ of the PM and $71 \%$ of the MS, p < 0.001).

\section{Treatment over 24 months}

Over the 24-month period, only a third (31\%) of the population had no change in treatment (34\% in the PM, 24\% in the MS). Including the $31 \%$ of patients lost to followup over 24 months, $35 \%$ of the patients who had initiated a monotherapy at baseline maintained it over the period ( $45 \%$ for the PM, $21 \%$ for the MS, $\mathrm{p}<0.001$ ), and $30 \%$ of the patients initiating a combination also maintained it (32\% for the PM and $27 \%$ for the MS, $\mathrm{p}=0.168$ ). Over the 24-month follow-up period, $39 \%$ of the patients who had initiated an atypical antipsychotic treatment maintained it, $36 \%$ for anticonvulsants, $45 \%$ for lithium and $20 \%$ for typical antipsychotics. $35 \%$ of the patients taking antide- pressants at baseline maintained the treatment over the 24 months. The proportion of patients taking atypical antipsychotics was stable (56\%) over the study period. The AAP + Lithium combination was common in the MS group ( $28 \%$ vs. $18 \%$ ), while the AAP + anticonvulsant combination was frequent in the PM (56\% vs. 39\%). Lithium was prescribed more frequently in the MS group (24\% vs. $16 \%, \mathrm{p}=0.025)$.

Antidepressant prescriptions were stable and common in both groups (55\% for the MS and $27 \%$ for the PM, p < 0.001 ). Prescriptions of anxiolytics decreased slightly over the 24 months, with $39 \%$ of patients treated with benzodiazepines at 24 months.

\section{Discussion}

The French cohort of the EMBLEM study followed over 24-months showed considerable use of antimanic combinations and concomitant treatments, in particular antide- 
Table 3: Course of the illness over 24 months.

\begin{tabular}{|c|c|c|}
\hline & Pure Mania & Mixed episode \\
\hline & $\begin{array}{c}\text { Over } 24 \text { months } \\
\quad n=364\end{array}$ & $\begin{array}{c}\text { Over } 24 \text { months } \\
n=164\end{array}$ \\
\hline \multicolumn{3}{|l|}{ Course: } \\
\hline$\rightarrow$ Relapse $^{(I)}(\%$, IC $95 \%)$ & $53 \%[49 \%, 58 \%]$ & $57 \%[50 \%, 63 \%]$ \\
\hline$\rightarrow$ Recurrence (2) (\%, IC $95 \%)$ & $12 \%[9 \%, 16 \%]$ & $19 \%[13 \%, 26 \%]$ \\
\hline$\rightarrow$ Remission (3) (\%, IC $95 \%)$ & $61 \%[56 \%, 66 \%]$ & $62 \%[55 \%, 69 \%]$ \\
\hline$\rightarrow$ Recovery ${ }^{(4)}(\%$, IC $95 \%)$ & $46 \% *[41 \%, 51 \%]$ & $36 \% *[30 \%, 42 \%]$ \\
\hline
\end{tabular}

Percentages are based on the Survival distribution (Kaplan-Meier estimations).

(I) Relapse: - Maintenance phase (24 months) only: Patients not achieving remission and if the patient meets one of the 3 following relapse criteria:

- Increase in CGI-BP Total since the last visit, with a score of 4 or more

- Admission to hospital for an acute episode of bipolar disorder - Psychiatrist's opinion, the patient has experienced a relapse since the last interview

(2) Recurrence: - Maintenance phase (24 months) only: If the patient is in remission and then met one of the three previous relapse criteria.

(3) Remission: Maintenance phase (24 months) only: patient with a CGI-BP Overall under 3 for 2 consecutive visits with no relapse between the visits. If the patient is lost to follow-up, the remission is considered as a missing data.

(4) Recovery: - Maintenance phase (24 months): Patient is in functional remission (remission and not dissatisfied with life) and social functioning is adequate (i.e. no work impairment, independent accommodation and at least 4 social activities in the previous 4 weeks OR with a partner (live-in or not live-in)).

$*=$ There is a significant difference between the Pure Mania and mixed episode patient groups, with a risk $\alpha=0.05$.

pressants. Mixed states were common and their illness prognosis was poorer compared to the pure mania patients.

Analysis of the EMBLEM cohort provides information on the follow-up, treatment and course of bipolar disorder over the 24-month period. With six out of ten patients in remission during the follow-up period, EMBLEM provides confirmation that long-term treatment of bipolar disorders brings lasting attenuation of bipolar symptoms. Following the difference observed between the rates of relapse and the rates of recurrence, it could be thought that once stabilization has been achieved, antimanic drugs are relatively efficacious in the long term, with lower rates of recurrence.

\section{Characteristics of mixed states}

The prevalence of MS at baseline in the French cohort of EMBLEM was $34 \%(n=262)$, in line with two other cohorts EPIMAN [5] and EPIMAN-II-Mille [16] (respectively $37 \%$ and $30 \%$ ), which used a different categorical definition, but higher than in the European EMBLEM cohort (24\%). It could be considered that, in France, psychiatrists are more attuned to identifying the associated depressive symptoms.
The study confirms the characteristics that were previously associated with MS in studies involving small populations (except for the EPIMAN-II-Mille study): patients are predominantly female $[5,16]$, with a higher risk of suicide $[7,16]$, earlier appearance of bipolar symptoms, a higher occurrence of manic episodes and depressive episodes in the past 12 months [9] and rapid cycling [17]. Comorbidity related to substance abuse and dependence commonly identified in the literature $[4,16,18,19]$ was not found; although there was no standardized instrument for addiction screening in the present study.

At 24 months, mixed state patients had a lower recovery rate than pure mania patients $(36 \%$ vs. $46 \%$, p $=0.006)$, with a comparable "simple" remission rate. This observation highlights the lasting nature of the functional issues associated with MS (significantly higher work impairment and dissatisfaction with life) and a residual clinical symptomatology showing significantly higher CGI-BP-depression and hallucination scores and more attempted suicides. The course of MS seems worse than in PM patients, with higher rates of recurrence and 1.5 times more MS experiencing recurrence, although these failed to reach significance.

These observations highlight the importance of systematic screening in mania co-occurring with depressive symptoms [4] and a specific course of care.

The observations also suggest, that for certain patients, the persistent nature of residual symptoms can have an effect on bipolar patients' quality of life and predispose relapse [20].

\section{Medication}

Antimanic treatment combinations

Treatments initiated for pure mania and mixed states in this study were characterized by a high proportion of combinations throughout the 24-month period, although less than one patient out of three maintained the same combination. Guidelines for treating an acute manic episode, however, recommend initiating monotherapy $[1,2]$. The number of mixed state patients with a poorer prognosis and which are harder to stabilize could partly explain the high proportion of treatment combinations.

The study design suggested including an equivalent number of patients taking olanzapine and other oral antimanic drugs. Analysis of the medications prescribed does not, therefore, give a precise picture of current practice, especially as regards the use of the various antimanic drugs, but it can offer a better understanding of prescriptions of combinations with atypical antipsychotic agents. AAP agents are frequently prescribed in combination with anticonvulsants or lithium, with a higher proportion of $\mathrm{AAP}+$ anticonvulsants in PM patients and AAP + lithium 
Table 4: Medication at baseline and at 24 months

\begin{tabular}{|c|c|c|c|c|c|c|}
\hline & \multicolumn{3}{|c|}{ Pure Mania } & \multicolumn{3}{|c|}{ Mixed episode } \\
\hline & $\begin{array}{l}\text { Baseline } \\
\mathrm{n}=504\end{array}$ & Treatment of the episode & $\begin{array}{l}24 \text { Months } \\
n=364\end{array}$ & $\begin{array}{l}\text { Baseline } \\
\mathrm{n}=262\end{array}$ & Treatment of the episode & $\begin{array}{c}24 \text { Months } \\
\mathrm{n}=164\end{array}$ \\
\hline \multicolumn{7}{|l|}{ Antimanic treatment: } \\
\hline \multicolumn{7}{|l|}{ Types of therapy $(n, \%):$} \\
\hline None & $184(37 \%)$ & 0 & $9(2 \%)^{*}$ & $99(38 \%)$ & 0 & $15(9 \%)^{*}$ \\
\hline Monotherapy & $191(38 \%)$ & $187(37 \%)^{*}$ & I $80(50 \%)^{*}$ & $99(38 \%)$ & $132(50 \%)^{*}$ & $79(48 \%)^{*}$ \\
\hline Combination & $129(26 \%)$ & $317(63 \%) *$ & 175 (48\%)* & $64(24 \%)$ & $130(50 \%)^{*}$ & $70(43 \%)^{*}$ \\
\hline \multicolumn{7}{|l|}{$\begin{array}{l}\text { No. of drugs related to the } \\
\text { treatment }(\mathrm{n}, \%) \text { : }\end{array}$} \\
\hline None & $184(37 \%)$ & 0 & $9(2 \%)^{*}$ & $99(38 \%)$ & 0 & $15(9 \%)^{*}$ \\
\hline I & $191(38 \%)$ & 187 (37\%) & $180(49 \%)^{*}$ & $99(38 \%)$ & 132 (50\%) & $79(48 \%) *$ \\
\hline 2 & $98(19 \%)$ & $24 \mid(48 \%)$ & 145 (40\%)* & $41(16 \%)$ & 103 (39\%) & $56(34 \%)^{*}$ \\
\hline 3 and + & $31(6 \%)$ & $76(15 \%)$ & $30(8 \%)^{*}$ & $23(9 \%)$ & $27(10 \%)$ & $14(9 \%)^{*}$ \\
\hline \multicolumn{7}{|l|}{$\begin{array}{l}\text { Types of treatment: } \\
\text { (n,\% Compared to the population) }\end{array}$} \\
\hline Lithium & $64(13 \%)$ & 70 (14\%) & $57(16 \%)^{*}$ & $36(14 \%)$ & 40 (15\%) & $39(24 \%)^{*}$ \\
\hline Anticonvulsant & $161(32 \%)$ & $296(59 \%)$ & $187(5 \mid \%)$ & $79(30 \%)$ & $147(56 \%)$ & 72 (44\%) \\
\hline Atypical antipsychotics. & 75 (I5\%) & $332(66 \%)$ & $212(58 \%)$ & $36(14 \%)$ & $153(58 \%)$ & $85(52 \%)$ \\
\hline Typical antipsychotics & I44 (29\%) & $163(32 \%)$ & $77(21 \%)$ & $75(29 \%)$ & $67(26 \%)$ & $34(21 \%)$ \\
\hline \multicolumn{7}{|l|}{ Compliance: } \\
\hline No prescription & $|3|(26 \%)$ & & $2(1 \%)^{*}$ & $60(23 \%)$ & & $5(3 \%)^{*}$ \\
\hline Compliance $\approx 100 \%$ & $253(50 \%)$ & & $336(92 \%)$ & $147(56 \%)$ & & $138(84 \%)$ \\
\hline Compliance $\approx 50 \%$ & $80(16 \%)$ & & $20(5 \%)$ & $45(17 \%)$ & & $17(10 \%)$ \\
\hline No compliance & $36(7 \%)$ & & $5(1 \%)$ & $8(3 \%)$ & & $3(2 \%)$ \\
\hline
\end{tabular}

\section{Course over 24 months:}

Maintains (since baseline) ( $\mathrm{n}, \%$ including LTFup):

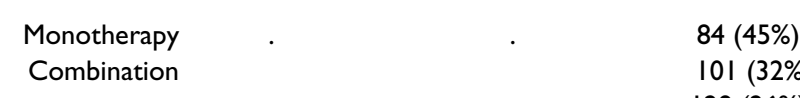

\begin{tabular}{|c|c|c|}
\hline 0 & $62(17 \%)$ & $33(20 \%)$ \\
\hline I & 59 (16\%) & $29(18 \%)$ \\
\hline 2 & $120(33 \%)$ & 63 (38\%) \\
\hline
\end{tabular}

\section{Concomitant treatments:}

$\begin{array}{rcc}\text { Antidepressants } & 139(28 \%)^{*} & 75(15 \%)^{*} \\ \text { Benzodiazepines } & 267(53 \%)^{*} & 291(58 \%)^{*} \\ \text { Anticholinergic drugs } & 44(9 \%) & 41(8 \%) \\ \text { Hypnotics (others) } & 156(31 \%) & 199(39 \%)\end{array}$

Types of antidepressant:

\begin{tabular}{|c|c|c|c|c|c|c|}
\hline Monotherapy(AD) (n, \%): & 134 (96\%) & 73 (97\%) & 93 (95\%) & 135 (98\%) & 127 (98\%) & 87 (96\%) \\
\hline IRSS & 104 (78\%) & $56(77 \%)$ & 74 (80\%) & $96(7 \mid \%)$ & $91(72 \%)$ & $65(75 \%)$ \\
\hline Tricyclic & 25 (19\%) & $13(18 \%)$ & 17 (I8\%) & $21(16 \%)$ & $15(12 \%)$ & $16(18 \%)$ \\
\hline Others & $5(4 \%)$ & $4(5 \%)$ & $2(2 \%)$ & $18(13 \%)$ & $21(17 \%)$ & $6(7 \%)$ \\
\hline Combination of $A D(n, \%)$ : & $5(4 \%)$ & $2(3 \%)$ & $5(5 \%)$ & $3(2 \%)$ & $2(2 \%)$ & $4(4 \%)$ \\
\hline
\end{tabular}

Compliance: the patient nearly always complies with/accepts his/her treatment for bipolar disorders $(\approx 100 \%)$, half the time $(\approx 50 \%)$

$*=$ There is a significant difference between the Pure Mania and mixed episode patient groups, threshold $\alpha=0.05$.

$\begin{array}{cccc}98(27 \%)^{*} & 138(53 \%)^{*} & 129(49 \%)^{*} & 91(55 \%)^{*} \\ 132(37 \%) & 177(68 \%)^{*} & 187(71 \%)^{*} & 74(45 \%) \\ 21(6 \%) & 21(8 \%) & 27(10 \%) & 10(6 \%) \\ 78(21 \%) & 92(35 \%) & 97(37 \%) & 43(26 \%) \\ & & & \\ 93(95 \%) & 135(98 \%) & 127(98 \%) & 87(96 \%) \\ 74(80 \%) & 96(71 \%) & 91(72 \%) & 65(75 \%) \\ 17(18 \%) & 21(16 \%) & 15(12 \%) & 16(18 \%) \\ 2(2 \%) & 18(13 \%) & 21(17 \%) & 6(7 \%) \\ 5(5 \%) & 3(2 \%) & 2(2 \%) & 4(4 \%)\end{array}$

- 
in MS patients. A number of studies have highlighted a limited efficacy of lithium in MS patients $[1,19,21]$. Combinations of AAP and Lithium or Valproate are recommended for severe forms in several guidelines [1].

\section{Concomitant treatments}

One of the important outcomes of this study was the frequent use of antidepressants and this was also seen in the European cohort [22]. Similar prescription patterns of antidepressants in mania have already been reported $[16,23]$.

The use of antidepressants, however, is not indicated [1,2] in the treatment of manic or mixed episodes, due to a risk of inducing mood switches [23] and rapid cycling [21]. It is possible that in this cohort, the high occurrence of MS explains the high rate of prescription of antidepressants as much as the high rate of prescription of antidepressants can explain the transition to an MS.

A number of explications can be put forward for the level of antidepressant prescriptions, with in first position the frequent co-occurrence of depressive symptoms with manic states. Three times more antidepressants are prescribed for an MS episode than for a PM episode. Mixedstate episodes do not by themselves, however, explain the total number of prescriptions. 15\% of PM patients were prescribed an antidepressant for the initial treatment of their episode, and more than one out of four over the 24 months. There are other reasons relating to why the physician prescribed or maintained an antidepressant, such as the continuation of a prescription for a previous depression, misgivings concerning a brutal discontinuation of antidepressants, anxiety concerning a depressive switch, the patient's insistence on maintaining his/her treatment and also certain psychopathological hypotheses which consider that mania constitutes a depressive equivalent which needs to be treated, etc.

Benzodiazepines (BZD) are also commonly prescribed, both initially and over the long term, especially for MS patients. BZDs are used when treating an acute episode of agitation $[1,2]$, but they are not recommended for longterm use. The brutal and disconcerting mood swings in the mixed states can contribute to the anxiety frequently experienced in such cases and can explain the high prescription levels $[16,18,24]$. For patients suffering from associated anxiety disorders, certain guidelines recommend using an atypical antipsychotic over the long term [2].

\section{Study limitations}

This was a prospective observational study, which is subject to the usual biases related to this kind of study, in particular observation biases. The effect of the study design, which requested investigators to include an equivalent number of patients prescribed olanzapine and those taking other antimanic drugs, was discussed above in the analysis of prescription patterns.

The post hoc dimensional definition of mixed states in the study is an important limitation that needs to be factored into the interpretation of the results. Although the inclusion criteria specified that mixed states should be included in the same way as pure mania episodes, MS diagnosis was not reported separately. The definition chosen is likely to include states that are significantly different to pure mixed states, especially as regards states associating depressive and manic symptoms to varying degrees, such as dysphoric mania or mixed depressions $[4,6,17]$. However, the chosen CGI-BP-mania and depression thresholds $(>3)$ were strict enough for most of these states to be considered as pure mixed states. This post hoc analysis is important in that it confirms the frequency of a clinically-significant associated depressive symptomatology in mania and measures the effect on the course and treatment patterns of bipolar disorder.

\section{Conclusion}

In the EMBLEM study, mixed states are common and their progression patterns are generally more severe. Screening of mixed states remains a major therapeutic issue and it is essential to systematically test for mixed-state items during an acute episode. In addition, the reasons for the high level of prescriptions of antidepressants both initially and long-term still need to be further investigates and should be considered as part of the current debate concerning the long-term use of antidepressants in bipolar disorders and of international guidelines which proscribe their use in manic and mixed episodes.

\section{Competing interests}

Jean-Michel Azorin has undertaken consultancy work for Lilly, Aventis, Janssen, Lundbeck, Astra Zeneca and BMS; he has received honoraria and hospitality from Lilly, Janssen, Lundbeck, BMS, Pfizer and Novartis in relation to conference presentations.

This study was sponsored by Eli Lilly and company. Catherine Reed, Michael Lukasiewicz and Elodie Aubrun are currently working for Eli Lilly.

\section{Authors' contributions}

JMA and IG were expert advisors for France in the EMBLEM study so have participated in the study design and drafted the manuscript. JB has performed the statistical analysis. ML and EA drafted the manuscript. CR has reviewed the manuscript. All authors read and approved the final manuscript. 


\section{Acknowledgements}

The authors gratefully acknowledge the study team and all the French investigators of EMBLEM. Investigators received economic compensation for inclusion and follow-up of included patients.

The authors also acknowledge Diego Novick and Hélène Sapin for reviewing the manuscript

\section{References}

I. American Psychiatric Association (APA): Guidelines for the treatment of patients with bipolar disorder (revision). Am J Psychiatry 2002, I 59(Suppl 4): I-50.

2. National Institute for health and Clinical Excellence (NICE): The management of bipolar disorder in adults, children and adolescents, in primary and secondary care. NICE Clinical Guideline 2006, 38: [http://www.nice.org.uk].

3. American Psychiatric Association (APA): Diagnostic and Statistical Manual of Mental Disorders. 4th edition. American Psychiatric Publishing Inc., Washington, DC; 1994.

4. McElroy SL: Understanding the complexity of bipolar mixed episodes. J Clin Psychiatry 2008, 69(2):e6.

5. Akiskal HS, Hantouche EG, Bourgeois ML, Azorin JM, Sechter D, Allilaire JF, Lancrenon S, Fraud JP, Châtenet-Duchêne L: Gender, temperament, and the clinical picture in dysphoric mixed mania: findings from a French national study (EPIMAN). J Affect Disord 1998, 50:175-186.

6. Ghaemi N: All mixed up: On the absence of diagnostic guidelines for mixed states in the ISBD Diagnostic Guidelines Task Force Report. Bipolar Disorder 2008, I 0: I29-I30.

7. Frye MA: Diagnostic Dilemnas and clinical correlates of Mixed states in bipolar disorder. I Clin Psychiatry 2007, 68: I2.

8. Goetz I, Tohen M, Reed C, Lorenzo M, Vieta E, EMBLEM Advisory Board: Functional impairment in patients with mania: baseline results of the EMBLEM study. Bipolar Disord 2007, 9(I2):45-52.

9. Haro JM, Van Os J, Vieta E, Reed C, Lorenzo M, Goetz I, EMBLEM Advisory Board: Evidence for three distinct classes of 'typical', 'psychotic' and 'dual' mania: results from the EMBLEM study. Acta Psychiatr Scand 2006, I I3(2): I I 2-120.

10. Montoya A, Perez Sanchez Toledo J, et al.: Patterns of drug treatment for manic episode in the clinical practice. Outcomes of the Spanish sample in the EMBLEM study. Actas Esp Psiquiatr 2007, 35:315-322.

II. Schuepbach D, Goetz I, Boeker H, Hell D: Voluntary vs. involuntary hospital admission in acute mania of bipolar disorder: results from the Swiss sample of the EMBLEM study. J Affect Disord 2006, 90:57-6I.

12. Vieta E, Panicali F, Goetz I, Reed C, Comes M, Tohen M, the EMBLEM Adversory Board: Olanzapine monotherapy and olanzapine combination therapy in the treatment of mania: 12-week results from the European Mania in Bipolar Longitudinal Evaluation of Medication (EMBLEM) observational study. J Affect Disord 2007, I06(I):63-72.

13. Young RC, Biggs JT, Zeigler VE: rating scale for mania: reliability, validity and sensitivity. $\mathrm{Br} J$ Psychiatry 1978, I 33:429-435.

14. Gonzalez-Pinto A, Ballesteros J, Aldama A, Perez de Heredia JL, Gutierrez M, Mosquera F, Gonzalez-Pinto A: Principal components of mania. J Affect Disord 2003, 76:95-102.

I5. Spearing MK, Post RM, Leverich GS, Brandt D, Nolen W: Modification of the Clinical Global Impressions (CGI) scale for use in bipolar illness (BP): the CGI-BP. Psychiatry Res 1997, 73:|59-|7|.

16. Hantouche E, Akiskal HS, Azorin JM, et al.: Clinical and psychometric characterization of depression in mixed mania: a report from the French National Cohort of 1090 maniac patients. J Affect Disord 2006, 96:225-232.

17. McElroy SL, Keck PE, Pope HG, Hudson Jl, Faedda GL, Swann AC: Clinical and research implications of the diagnosis of dysphoric or mixed mania or hypomania. Am J Psychiatry 1992, | 49:1633-1644.

18. Goldberg JF: Bipolar Mixed Episodes: characteristics and comorbidities. J Clin Psychiatry 2007, 68:I2.
19. Thuile J, Even C, Guelfi JD: Traitement des états mixtes dans le trouble bipolaire de I'humeur. L'Encéphale 2005, 3 I:6 I7-23. cahier I

20. Goldberg JF, Harrow M: Subjective life satisfaction and objective functional outcome in bipolar and unipolar mood disorders: a longitudinal analysis. J Aff Disord 2005, 89:79-89.

21. Fountoulakis KN, Vieta E, Siamouli M, Valenti M, Magiria S, Oral T, Fresno D, Giannakopoulos P, Kaprinis G: Treatment of bipolar disorder: a complex treatment for a multi-faceted disorder. Annals of General Psychiatry 2007, 6:27.

22. Rosa AR, Cruz N, Franco C, Haro MJ, Bertsch J, Reed C, Aarre T, Sanchez-Moreno J, Vieta E: Why do clinicians maintain antidepressants in some patients with acute mania? Hints from a large, naturalistic study (EMBLEM). J Clin Psy 2009 in press.

23. Truman CI, Goldberg JF, Ghaemi N, Baldassano CF, Wisniewski SR, Dennehy EB, Thase ME, Sachs GS: Self-reported history of Manicl Hypomanic switch associated with antidepressant use: Data from the Systematic Treatment Enhancement Program for Bipolar Disorder (STEP-BD). J Clin Psychiatry 2007, 68: I0.

24. Mclntyre RS: Acute treatment of patients with bipolar Mixed Episodes. J Clin Psychiatry 2007, 68(12): | 97|-81.

\section{Pre-publication history}

The pre-publication history for this paper can be accessed here:

http://www.biomedcentral.com/1471-244X/9/33/pre pub
Publish with Bio Med Central and every scientist can read your work free of charge

"BioMed Central will be the most significant development for disseminating the results of biomedical research in our lifetime. "

Sir Paul Nurse, Cancer Research UK

Your research papers will be:

- available free of charge to the entire biomedical community

- peer reviewed and published immediately upon acceptance

- cited in PubMed and archived on PubMed Central

- yours - you keep the copyright

Submit your manuscript here:

http://www.biomedcentral.com/info/publishing_adv.asp 